\section{Selective Cytotoxicity of Mycophenolic Acid against Transformed Cells}

\section{Yoichi Hayakawa, Kin-Ya SOHDa and HARUO SETO}

Institute of Molecular and Cellular Biosciences, The University of Tokyo,

Bunkyo-ku, Tokyo 113, Japan

(Received for publication May 10, 1995)

The retinoblastoma tumor suppressor protein (pRB) plays a central role in mammalian cell cycle control and is inactivated during the development of a wide variety of human cancers ${ }^{1)}$. Human papillomaviruses (HPV) are highly associated with human cervical cancers and encode E6 and E7 oncoproteins, which bind and inactivate the tumor suppressors $\mathrm{p} 53$ and $\mathrm{pRB}$, respectively ${ }^{2}$.
In order to search for antitumor substances with selective cytotoxicity against transformed cells, we established immortalized cell lines with $\mathrm{pRB}$ inactivated by HPV16 E7 oncoprotein. Primary rat glia cells obtained from Wistar rat (18-day embryo) cerebral cortex were transfected with plasmids containing a neomycin-resistant gene and HPV16 E7 or both E6 and E7 oncogenes (pSVneo-E7P and pSVneo-E6E7) ${ }^{3}$ by the calcium phosphate method ${ }^{4)}$. Drug-resistant colonies were selected by incubation for 3 weeks in the presence of

Fig. 1. Structure of mycophenolic acid.<smiles>COc1c(C)c2c(c(O)c1C/C=C(\C)CCC(=O)O)C(=O)OC2</smiles>

Fig. 2. Effect of MPA on the viability of normal and transformed rat glia cells.

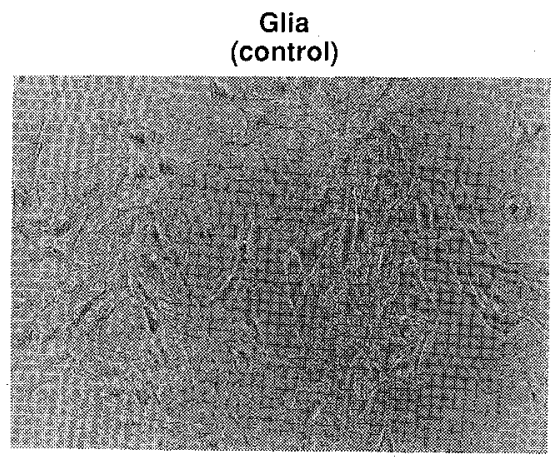

RG-E7-6f (control)

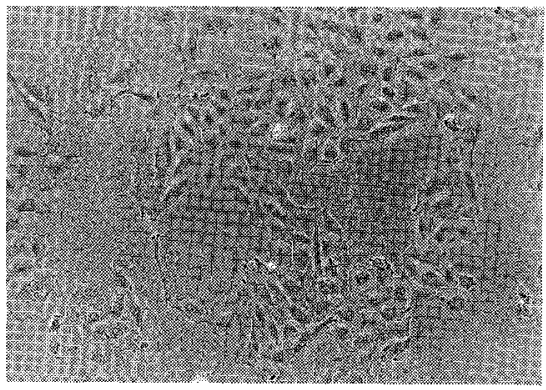

RG-E6E7-3d (control)

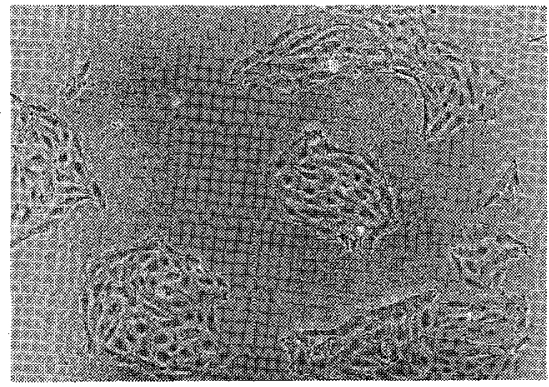

Glia

(mycophenolic acid, $5 \mu \mathrm{g} / \mathrm{ml}$ )

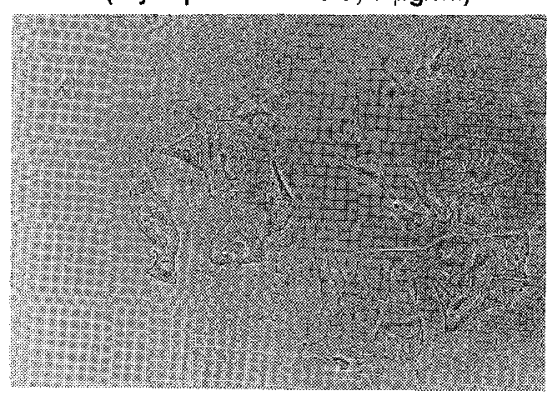

RG-E7-6f

(mycophenolic acid, $5 \mu \mathrm{g} / \mathrm{ml}$ )

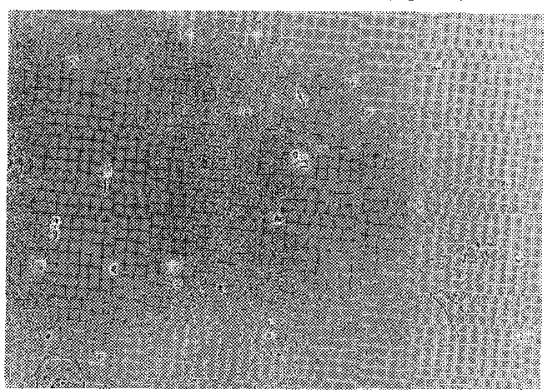

RG-E6E7-3d

(mycophenolic acid, $5 \mu \mathrm{g} / \mathrm{ml}$ )

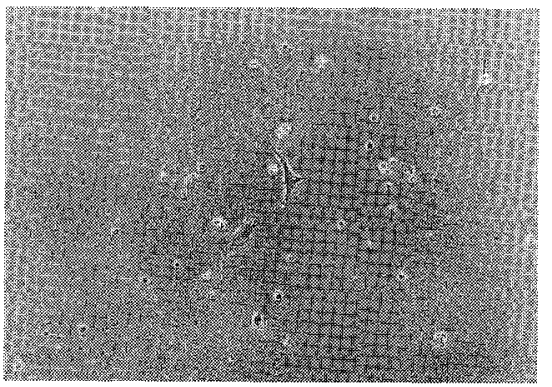

Cells were cultured for 72 hours in DULBECCo's modified EAGLE's medium supplemented with $10 \%$ fetal calf serum and $0.1 \%$ glucose in the presence or absence of $5 \mu \mathrm{g} / \mathrm{ml}$ of MPA. 
Fig. 3. Effect of MPA on the growth of normal and transformed rat glia cells in the presence or absence of guanosine.

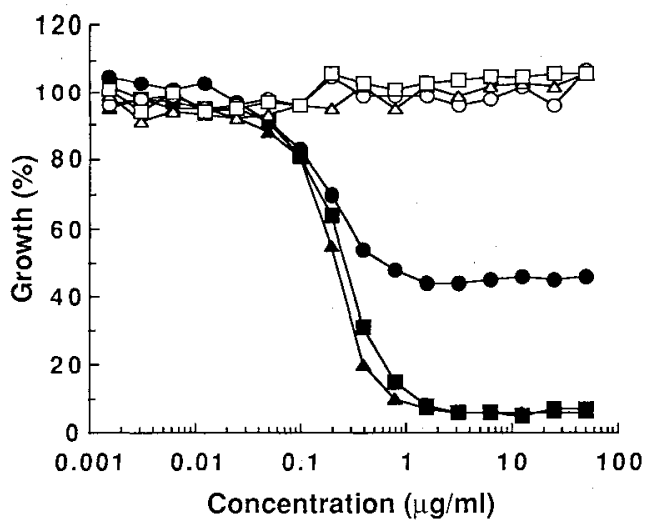

Cells were cultured with various concentrations of MPA for 72 hours in DulBeCCo's modified EAGLE's medium supplemented with $10 \% \mathrm{~d}$ fetal calf serum and $0.1 \%$ glucose in the absence $(\bullet, \Delta, \square)$ or presence $(O, \Delta, \square)$ of $100 \mu \mathrm{g} / \mathrm{ml}$ of guanosine, and then the growth was measured by the MTT method. •, O Glia cells; $\Delta, \triangle$ RG-E7-6f cells; $\mathbf{\square}, \square$ RG-E6E7-3d cells.

$400 \mu \mathrm{g} / \mathrm{ml}$ of $\mathrm{G} 418$, a neomycin analogue. Twelve weeks after transfection, immortalized cells were cloned by limiting dilution and designated RG-E7-6f and RGE6E7-3d cell lines.

In the course of our screening for antitumor antibiotics by using these transformed cells, a fungal strain was found to produce an active substance, which was identified as mycophenolic acid (MPA) based on its physicochemical properties and NMR data. The structure of MPA is shown in Fig. 1.

MPA induced cell death against transformed glia cells (RG-E7-6f and RG-E6E7-3d). In contrast, MPA arrested the growth of normal glia cells without cytotoxicity. The viability of the cells treated with $5 \mu \mathrm{g} / \mathrm{ml}$ of MPA is illustrated in Fig. 2. Since MPA is known to be a potent inhibitor of inosinate dehydrogenase, a key enzyme of guanine nucleotide biosynthesis ${ }^{6}$, the effect of MPA on the cell growth with or without guanosine was examined by formazan formation after treatment of the cells with $0.5 \mathrm{mg} / \mathrm{ml}$ of 3-(4,5-dimethylthiazol-2-yl)-2,5diphenyltetrazolium bromide (MTT). As shown in Fig. 3, $100 \mu \mathrm{g} / \mathrm{ml}$ of guanosine completely prevented the activity of MPA, suggesting that the cytotoxic and cytostatic effects of MPA are mediated via reduction of a guanine nucleotide pool.

The activity of MPA was further investigated using normal and transformed $3 Y 1$ rat fibroblasts ${ }^{7 \sim 9)}$. All 3Y1 cell lines were obtained from Japanese Cancer Research Resources Bank. The results are summarized in Fig. 4. MPA induced growth arrest against normal 3Y1 cells and v-H-ras-transformed cells (HR-3Y1), and caused cell death against $3 \mathrm{Y} 1$ cells transformed with simian virus 40 (SV-3Y1) and adenovirus type 12 (Ad12-3Y1). Cells transformed with v-src (SR-3Y1) exhibited an inter-
Fig. 4. Effect of MPA on the growth of normal and transformed rat $3 \mathrm{Y} 1$ fibroblasts.

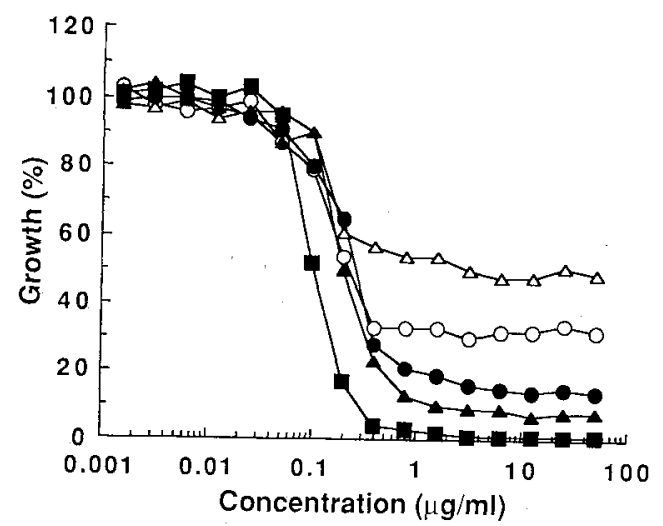

Cells were cultured with various concentrations of MPA for 72 hours in DULBECCo's modified EAGLE's medium supplemented with $10 \%$ heat-inactivated fetal calf serum and $0.1 \%$ glucose, and then the growth was measured by the MTT method. $03 \mathrm{Y} 1, \triangle \mathrm{HR}-3 \mathrm{Y} 1, \bullet \mathrm{SR}-3 \mathrm{Y} 1, \triangle \mathrm{SV}-3 \mathrm{Y} 1$, - Ad12-3Y1 cells.

Fig. 5. Flow cytometric cell cycle analysis of $3 Y 1$ cells.
Control

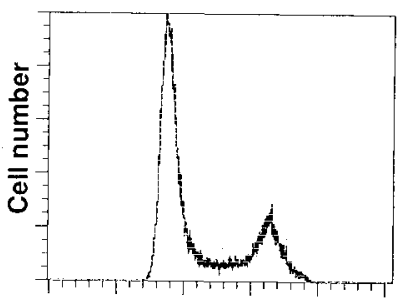

Relative DNA content
Mycophenolic acid $(5 \mu \mathrm{g} / \mathrm{ml})$

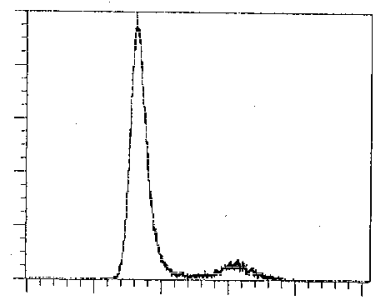

Relative DNA content
Cells in $\mathrm{Gl}$ phase, G2/M phase and $\mathrm{S}$ phase are represented by the first peak, the second peak and the area between the peaks, respectively.

mediate sensitivity to MPA-induced cytotoxicity.

Flow cytometric analysis on a Beckton Dickinson FACScan instrument revealed that MPA arrested the cell cycle of $3 \mathrm{Y} 1$ cells in G1 phase as shown in Fig. 5.

Cell lines highly sensitive to the killing effect of MPA commonly express viral oncoproteins including HPV E7, adenovirus E1A and simian virus 40 large $\mathrm{T}$ antigen, which can bind and inactivate $\mathrm{pRB}$. Since inactivation of pRB by phosphorylation is required for progression from G1 into $S$ phase, MPA seems to inhibit phosphorylation of $\mathrm{pRB}$ in normal cells. The inappropriate entry of pRB-inactivated cells into $S$ phase under limiting concentration of dGTP might cause a DNA replication error and cell death.

MPA has been reported to reveal excellent antitumor activity in vivo and no toxicity in mice $\left(\mathrm{LD}_{50}\right.$ $>1,000 \mathrm{mg} / \mathrm{kg}$, ip or po ${ }^{10)}$. In our assay system, other known antitumor antibiotics such as actinomycin $D$, adriamycin and mitomycin $\mathrm{C}$ showed cytotoxicity against normal glia cells and fibroblasts at their effective con- 
centrations (data not shown). Therefore, this system is useful to search for antitumor agents with low toxicity. Further biological studies on MPA are in progress.

\section{Acknowledgments}

We thank Dr. T. KANDA, National Institute of Health, Japan, for providing us with pSVneo-E7P and pSVneo-E6E7 plasmids. This work was supported in part by Grant-in-Aids for Scientific Research on Priority Areas from the Ministry of Education, Science and Culture, Japan and by UeharA Memorial Foundation.

\section{References}

1) Cobrinik, D.; S. Dowdy, P. Hinds, S. Mittnacht \& R. WEINBERG: The retinoblastoma protein and the regulation of cell cycling. Trends Biochem. Sci. 17: 312 315, 1992

2) VousDen, K.: Interaction of human papillomavirus transforming proteins with the products of tumor suppressor genes. FASEB J. 7: 872 879, 1993

3) Kanda, T.; S. WaTANABE \& K. YOSHIIKE: Immortalization of primary rat cells by human papillomavirus type 16 subgenomic DNA fragments controlled by the SV40 promoter. Virology 165: $321 \sim 325,1988$

4) Chen, C. \& H. OKayama: High-efficiency transformation of mammalian cells by plasmid DNA. Mol. Cell Biol. 7: $2745 \sim 2752,1987$
5) Birkinshiaw, J. H.; H. Raistrick \& D. J. Ross: Studies in the biochemistry of micro-organisms. 86. The molecular constitution of mycophenolic acid, a metabolic product of Penicillium brevi-compactum Dierckx. Part 3. Further observation on the structural formula for mycophenolic acid. Biochem. J. 50: 630 634, 1952

6) Lowe, J. K.; L. Brox \& J. F. Henderson: Consequences of inhibition of guanine nucleotide synthesis by mycophenolic acid and virazol. Cancer Res. 37: 726 743, 1977

7) Kimura, G.; A. ITAGaKr \& J. Summers: Rat cell line $3 Y 1$ and its virogenic polyoma- and SV40-transformed derivatives. Int. J. Cancer 15: 694 706, 1975

8) Zaitsu, H.; H. Tanaka, T. Mitsudomi, A. Matsuzaki, M. Ohtsu \& G. Kimura: Differences in proliferation properties among sublines of rat $3 \mathrm{Y} 1$ fibroblasts transformed by various agents in vitro. Biomed. Res. 9: $181 \sim$ 197,1988

9) Shimura, H.; T. Mitsudomi, A. Matsuzaki, M. Kabemura, A. OKudA \& G. Kimura: Transformation by $\mathrm{v}-\mathrm{H}$-ras does not restore proliferation of a set of temperature-sensitive cell-cycle mutants of rat $3 \mathrm{Y} 1$ fibroblasts. Cell Structure and Function 15: $211 \sim 219$, 1990

10) Williams, R. H.; D. H. Lively, D. C. Delong, J. C. Cline, M. J. Sweeney, G. A. Poore \& S. H. Larsen: Mycophenolic acid: Antiviral and antitumor properties. J. Antibiotics 21: 463 464, 1968 